\title{
Article \\ Study on the Control of Torque Distribution of 4WD Corn Harvester Operation Drive
}

\author{
Deyi Zhou, Pengfei Hou (D, Yuelin Xin, Xinlei Lv, Baoguang Wu *, Haiye Yu, Jinsong Zhang and Qiang Zhang \\ The College of Biological and Agricultural Engineering, Jilin University, 5988 Renmin Street, \\ Changchun 130025, China; zhoudy@jlu.edu.cn (D.Z.); houpf20@mails.jlu.edu.cn (P.H.); meijingaifan@163.com (Y.X.); \\ Lv2460375359@163.com (X.L.); haiye@jlu.edu.cn (H.Y.); jluzjs@jlu.edu.cn (J.Z.); zhangqiang@jlu.edu.cn (Q.Z.) \\ * Correspondence: wubg@jlu.edu.cn
}

Citation: Zhou, D.; Hou, P.; Xin, Y.; Lv, X.; Wu, B.; Yu, H.; Zhang, J.; Zhang, Q. Study on the Control of Torque Distribution of $4 \mathrm{WD}$ Corn Harvester Operation Drive. Appl. Sci. 2021, 11, 9152. https://doi.org/ 10.3390/app11199152

Academic Editor: Pietro Picuno

Received: 28 July 2021

Accepted: 28 September 2021

Published: 1 October 2021

Publisher's Note: MDPI stays neutral with regard to jurisdictional claims in published maps and institutional affiliations.

Copyright: (c) 2021 by the authors. Licensee MDPI, Basel, Switzerland. This article is an open access article distributed under the terms and conditions of the Creative Commons Attribution (CC BY) license (https:// creativecommons.org/licenses/by/ $4.0 /)$.

\begin{abstract}
In response to the poor adaptability of existing harvesters to complex operating conditions in the field, this study took a three-row four-wheel-drive (4WD) corn harvester as the research object, designed a traveling transmission system layout, proposed a control strategy of driving torque distribution, simulated, and analyzed each of the four states of harvester drive wheels slippage. The results showed that under the driving wheels slipping condition, after applying torque control, the adjustment time was $43.3 \%$ shorter than that without control in the case of single wheel slipping, $11.1 \%$ shorter than that without control in the case of two wheels slipping on the same axle, $41.4 \%$ shorter than that without control in the case of two wheels slipping on different axles, and $36.6 \%$ shorter than that without control in the case of three driving wheels slipping. The application of drive torque distribution control could significantly improve the traction and passing ability of the corn harvesters during operation, as well as made the harvester travel more smoothly, thus improving the harvest quality. The drive torque distribution control can be applied not only to the three-row corn harvester, but also to other types of harvesters, and self-propelled agricultural machinery to enhance their adaptability, improving their operation quality. It has a significant reference value for the development of the driving system on walking agricultural machinery.
\end{abstract}

Keywords: 4WD corn harvester; travel drive system; active torque distribution; drive wheel slip; simulation

\section{Introduction}

Corn is one of the most widely planted food crops in the world [1-3]. Mechanized corn harvesting is an essential part of corn production. However, due to the complex landscapes such as plateaus, hills, and mountains, which account for more than half of the total global land area and nearly $70 \%$ of the national territory in China, the cultivated landscapes are variable and complex, making the existing self-propelled agricultural machinery such as harvesters not well adapted to the complex operating environment in the fields $[4,5]$.

The New Holland CS series harvesters and the Clorox TUCAO series harvesters both used adaptive headers to increase their adaptability to the ground, ensure their harvest quality. Several scholars have designed self-balancing chassis to enhance the adaptability of the chassis to complex operating environments, increase operational safety, and improve operational quality [6,7]. Although these designs can reduce the impact of ground undulation on the operation quality to some extent, they cannot eliminate the impact of speed fluctuations caused by the slippage of the driving wheels of the travel machinery.

4WD (four-wheel-drive) can significantly reduce wheel slippage and improve the traction and driving stability of the vehicle [8,9]. 4WD torque distribution control could further improve the overall power performance of the travel machinery on this basis. 4WD torque control techniques have been studied extensively in inter-axle torque control, same-axle inter-wheel torque control, and integrated control. The research on inter-axle torque control mainly includes inter-axle differential characteristic analysis [10,11], torque distribution 
control research, and simulation analysis [12-15]. The research on inter-wheel torque control of the same axle mainly includes the design of differential structure [16-18], torque distribution control research, and simulation analysis $[19,20]$. The research on integrated control mainly focuses on the proposed control strategy and simulation analysis [21-24]. It has been proved that $4 \mathrm{WD}$ torque distribution control could effectively improve the traction, passing ability, and driving stability of the travel machinery. In this study, the $4 \mathrm{WD}$ torque distribution control technology was applied to the harvesters to solve the drive wheels slipping problem, reduce the speed fluctuation, enhance the passing ability and driving stability of the whole machine, and finally improve the operational performance of the harvesters.

In this study, a three-row wheeled 4WD corn harvester was used as the research object, a traveling transmission system layout was designed, the inter-axle and interwheel torque distribution devices were designed and optimized. The corn harvester had a large inertia, low speed, and high torque during operation, therefore electronically controlled disc brakes were used as a component to reduce the braking torque load by solidly connecting to the drive axles differential. Based on this travel drive system layout, a $4 \mathrm{WD}$ corn harvester drive torque distribution control strategy was proposed. The torque controller executed the control strategy controlling the corn harvester to complete a series of operations to eliminate drive wheel slip, adjust the whole machine operating posture, and enhance the field passing ability and driving stability of the harvester. The 4WD corn harvester drive torque distribution control was simulated by MATLAB/Simulink. The results showed that the applied torque distribution control of the $4 \mathrm{WD}$ corn harvester could significantly reduce the adjustment time when the drive wheels slipped, effectively reduce the speed fluctuation during the adjustment process, and immensely improve the field adaptability and operation quality of the corn harvester. This study provided a new method for the design and improvement of drive systems on harvesters and other walking agricultural machinery.

\section{Design and Modeling}

In this section, a torque distribution scheme for the three-row wheeled 4WD corn harvester was proposed. The inter-axle, inter-wheel torque distribution device, and brake mounting structure were optimized and designed. The mathematical models were established on this basis.

\subsection{Torque Distribution Scheme and Control Principle}

The torque distribution scheme of the corn harvester is shown in Figure 1. The power is output from the engine and transmitted to the automatic transmission through the V-belt, then the automatic transmission inputs the power to the inter-axle torque distribution device, finally the torque distribution device to actively distribute the torque between the front and rear axles. The torque on the rear-drive axle is freely distributed to the left and right drive wheels through the bevel gear differential, and the torque on the front drive axle is actively distributed to both drive wheels through the front drive axle inter-wheel torque distribution control device.

The drive torque control hardware mainly includes a torque controller, electronically controlled disc brakes, electronically controlled center differential, electronically controlled inter-axle differential, diesel throttle controller, and various sensors. Among them, the torque controller is the core. During operation, the torque controller managed the brakes, the electronically controlled center differential, and the diesel throttle controller to resolve torque distribution. When the drive wheel slip or a large speed difference between the front and rear drive axles, the torque controller will issue a corresponding control command after judging the status of the whole machine, control the brakes or inter-axle torque control device to prevent the drive wheels from slipping, and distribute the torque to other wellattached drive wheels, improve the traction of the whole machine. If the driving wheels 
still slip after control, it indicates that the engine output torque is too large, and the engine output torque needs to be adjusted by throttle control.

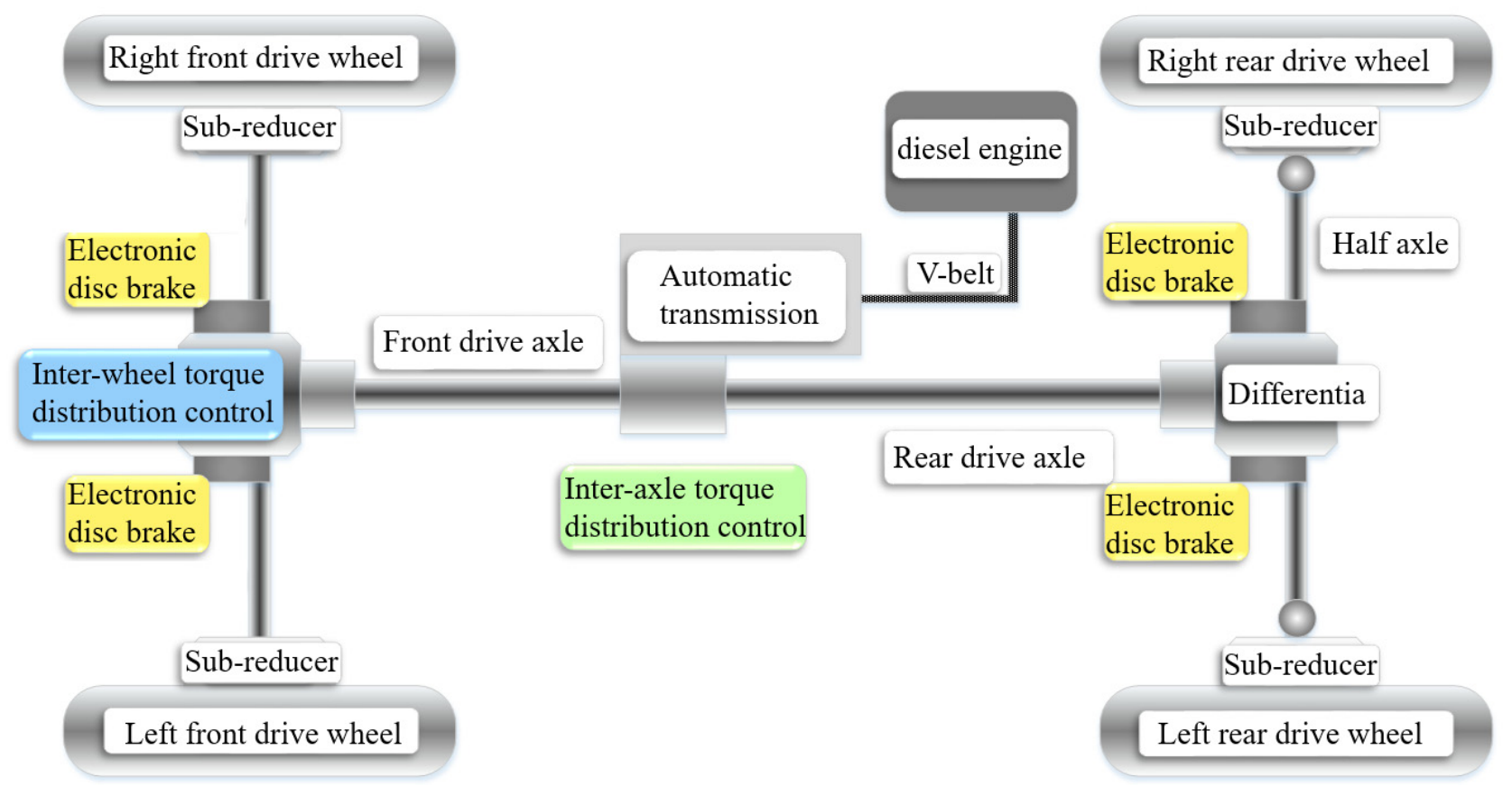

Figure 1. Torque distribution scheme of the 4WD harvester.

\subsection{Establishment of the Mathematical Model}

Based on the torque distribution scheme of the drive system, combining the specific structure of the inter-axle and inter-wheel torque distribution devices, the mathematical models of the whole machine, the inter-axle and inter-wheel torque distribution devices, the drive wheels, the engine, and the brakes were established.

\subsubsection{Mathematical Model of the Whole Machine}

Some explorations have been done on the vehicle model building by Wong et al. [25]. With reference to the vehicle model establishment, the following mechanics model of the harvester was established.

The forces condition of the whole harvester in the absolute coordinate system is shown in Figure 2, where the $x$ and $y$ axes are shown, and the $z$-axis points from the vehicle mass center to the outside of the paper. 


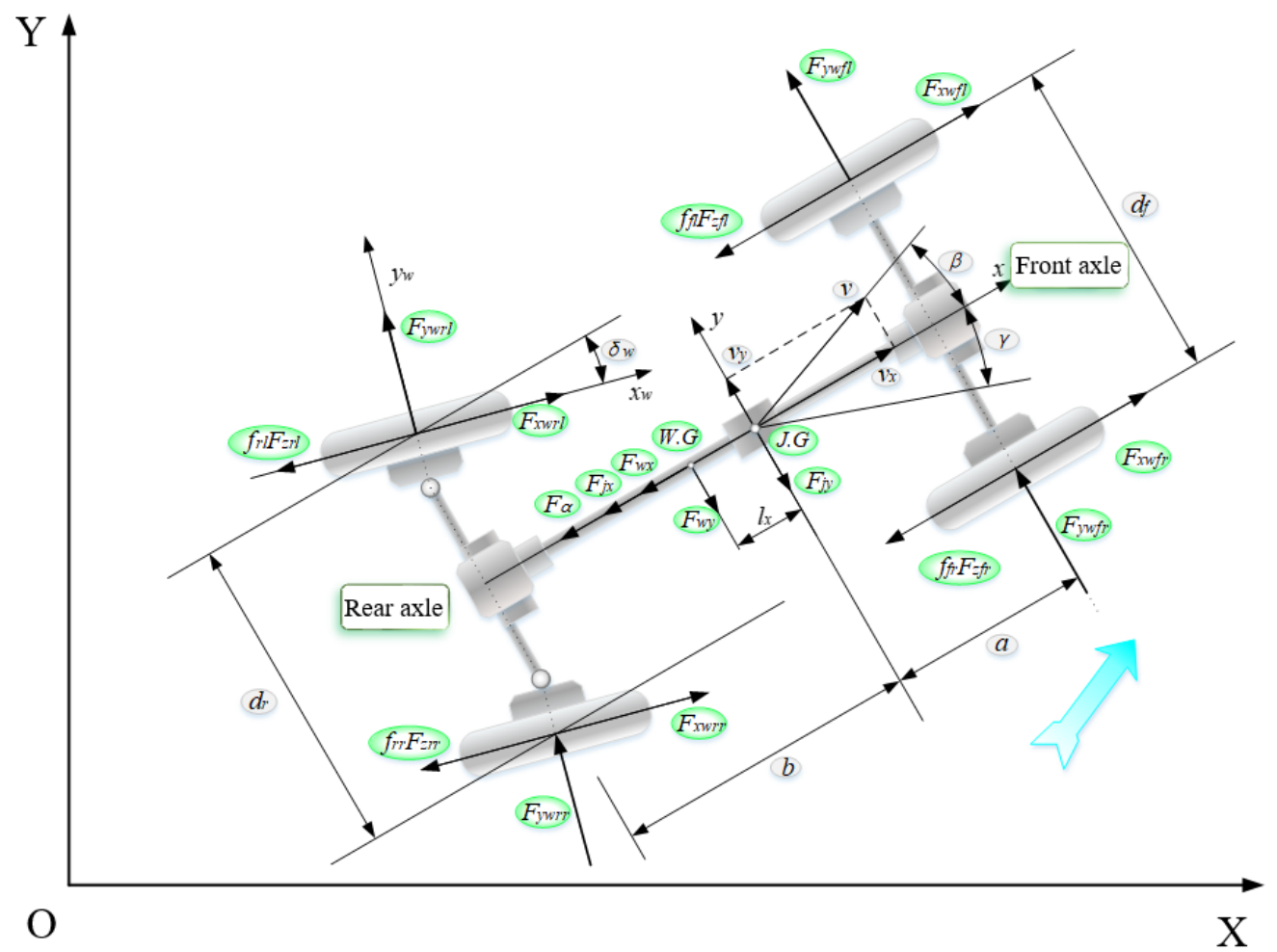

Figure 2. Forces on the whole harvester in the coordinate system.

In the coordinate system, after analyzing the force situation of the harvester, the following equilibrium equations for the whole machine along $x, y$ axes, and around the $z$-axis were established.

Transverse mechanical equilibrium equation:

$$
\begin{gathered}
m\left(a_{y}+V_{x} \dot{\gamma}\right)=\sum F_{y}=-\left(F_{x w r l}+F_{x w r r}\right) \sin \delta_{w}+F_{y w f l}+F_{y w f r} \\
+\left(F_{y w r l}+F_{y w r r}\right) \cos \delta_{w}+\left(f_{r l} F_{z r l}+f_{r r} F_{z r r}\right) \sin \delta_{w}-\frac{1}{2} C_{D y} A_{y} \rho V_{r y}^{2}
\end{gathered}
$$

longitudinal mechanical equilibrium equation:

$$
\begin{gathered}
m\left(a_{x}-V_{y} \dot{\gamma}\right)=\sum F_{x}=\left(F_{x w r l}+F_{x w r r}\right) \cos \delta_{w}+F_{x w f l}+F_{x w f r}+\left(F_{y w r l}+F_{y w r r}\right) \sin \delta_{w} \\
-\left(f_{r l} F_{z r l}+f_{r r} F_{z r r}\right) \cos \delta_{w}-f_{f l} F_{z f l}-f_{f r} F_{z f r}-\frac{1}{2} C_{D x} A_{x} \rho V_{r x}^{2}-m g \sin \alpha
\end{gathered}
$$

equation of moment balance around $z$-axis:

$$
\begin{aligned}
J_{z} \ddot{\gamma}= & \sum M_{z}=\left[\left(F_{x w r r}-F_{x w r l}+f_{r l} F_{z r l}-f_{r r} F_{z r r}\right) \cos \delta_{w}+\left(-F_{y w r l}+F_{y w r r}\right) \sin \delta_{w}\right] \frac{d_{r}}{2} \\
& +\left[\left(F_{x w r r}+F_{x w r l}-f_{r l} F_{z r l}-f_{r r} F_{z r r}\right) \sin \delta_{w}-\left(F_{y w r l}+F_{y w r r}\right) \cos \delta_{w}\right] b \\
+ & \left(F_{x w f r}-F_{x w f l}+f_{f l} F_{z f l}-f_{f r} F_{z f r}\right) \frac{d_{f}}{2}+\left(F_{y w f l}+F_{y w f r}\right) a+\frac{1}{2} C_{D y} A_{y} \rho V_{r y}^{2} l_{x}
\end{aligned}
$$

the harvester travels slowly during operation, the effect of wind speed on the harvester is small, therefore, neglected in the subsequent analysis [26]. The meaning of each parameter in the formula is shown in Table 1. 
Table 1. The meaning of each parameter in the formula.

\begin{tabular}{|c|c|c|c|}
\hline Parameters & Symbol & Parameters & Symbol \\
\hline Yaw rate & $\dot{\gamma}$ & $\begin{array}{c}\text { The sum of the moments of the whole machine } \\
\text { around the } z \text {-axis }\end{array}$ & $M_{z}$ \\
\hline Yaw angle & $\gamma$ & Steering angle of steering wheel & $\delta_{w}$ \\
\hline Yaw angular acceleration & $\ddot{\gamma}$ & The ground longitudinal forces on the tire & $F_{x w}$ \\
\hline Acceleration of the whole machine along $x$-axis & $a_{x}$ & Acceleration of the whole machine along $y$-axis & $a_{y}$ \\
\hline The ground transverse forces on the tire & $F_{y w}$ & The longitudinal stiffness of the tire & $C_{S}$ \\
\hline Tire longitudinal slip rate & $s_{S}$ & The transverse stiffness of the tire & $C_{a}$ \\
\hline Tire transverse slip rate & $s_{a}$ & Normal load on harvester tire & $F_{z}$ \\
\hline Longitudinal adhesion coefficient of tire & $\mu_{x}$ & Transverse adhesion coefficient of tire & $\mu_{y}$ \\
\hline Speed of the whole machine along the $x$-axis & $V_{x}$ & Speed of the whole machine along the $y$-axis & $V_{y}$ \\
\hline The sum external force along the $x$-axis & $F_{x}$ & The sum external force along the $y$-axis & $F_{y}^{y}$ \\
\hline Longitudinal force on the front left wheel & $F_{x w f l}$ & Lateral force on the front left wheel & $F_{y w f l}$ \\
\hline Longitudinal force on the front right wheel & $F_{x w f r}$ & Lateral force on the front right wheel & $F_{y w f r}$ \\
\hline Longitudinal force on the rear left wheel & $F_{x w r l}$ & Lateral force on the rear left wheel & $F_{y w r l}$ \\
\hline Longitudinal force on the rear right wheel & $F_{x w r r}$ & Lateral force on the rear right wheel & $F_{y w r r}$ \\
\hline Front left wheel rolling resistance radius & $f_{f l}$ & Front right wheel rolling resistance radius & $f_{f r}$ \\
\hline Rear left wheel rolling resistance radius & $f_{r l}$ & Rear right wheel rolling resistance radius & $f_{r r}$ \\
\hline Front left wheel-tire load & $F_{z f l}$ & Front right wheel tire load & $F_{z f r}$ \\
\hline Rear left wheel-tire load & $F_{z r l}^{-j l}$ & Rear right wheel tire load & $F_{z r r}$ \\
\hline $\begin{array}{l}\text { Wind resistance coefficient of the whole } \\
\text { machine along } x \text {-axis }\end{array}$ & $C_{d x}$ & $\begin{array}{l}\text { Wind resistance coefficient of the whole machine } \\
\text { along } y \text {-axis }\end{array}$ & $C_{d y}$ \\
\hline Frontal Area of the whole machine along $x$-axis & $A_{x}$ & Frontal Area of the whole machine along $y$-axis & $A_{y}$ \\
\hline $\begin{array}{l}\text { Relative velocity of the whole machine } \\
\text { and the wind along the } x \text {-axis }\end{array}$ & $V_{r x}$ & $\begin{array}{l}\text { Relative velocity of the whole machine } \\
\text { and the wind along the } y \text {-axis }\end{array}$ & $V_{r y}$ \\
\hline Air density & $\rho$ & Mass & $m$ \\
\hline Road slope & $\alpha$ & Side slip angle & $\beta$ \\
\hline Yaw angular acceleration & $\dot{\gamma}$ & Gravitational acceleration & $\mathrm{g}$ \\
\hline $\begin{array}{c}\text { Distance between the front axle and the center } \\
\text { of mass }\end{array}$ & $a$ & $\begin{array}{l}\text { Distance between the rear axle } \\
\text { and the center of mass }\end{array}$ & $b$ \\
\hline Front-wheel track & $d_{f}$ & Rear-wheel track & $d_{r}$ \\
\hline $\begin{array}{l}\text { Longitudinal distance between wind pressure } \\
\text { center and mass of the whole machine }\end{array}$ & $l_{x}$ & $\begin{array}{l}\text { Moment of inertia of the whole } \\
\text { machine around } z \text {-axis }\end{array}$ & $J_{z}$ \\
\hline Front left wheel angular acceleration & $\dot{\omega}_{f l}$ & Rear left wheel angular acceleration & $\dot{\omega}_{r l}$ \\
\hline Front right wheel angular acceleration & $\dot{\omega}_{f r}$ & Rear right wheel Angular acceleration & $\dot{\omega}_{r r}$ \\
\hline $\begin{array}{c}\text { The component of the gravity of the } \\
\text { harvester along the slope }\end{array}$ & $F_{\alpha}$ & $\begin{array}{l}\text { The central differential's front } \\
\text { axle angle acceleration }\end{array}$ & $\omega_{o f}$ \\
\hline Driving force of harvester & $F_{j}$ & Drive wheel tire radius & $r_{w}$ \\
\hline Front left brake torque & $M_{b f l}$ & Front right brake torque & $M_{b f r}$ \\
\hline Rear left brake torque & $M_{b r l}$ & Rear right brake torque & $M_{b r r}$ \\
\hline Front wheel moment of inertia & $j_{w f}$ & Contact length of tire with ground & $l_{n}$ \\
\hline Number of sun gear teeth & $Z_{t}$ & Number of teeth of the gear ring & $Z_{x}$ \\
\hline Front axle gearbox ratio & $i_{o f}$ & Rear axle gearbox ratio & $i_{o r}$ \\
\hline Front axle torque moment of inertia & $j_{f}$ & Rear axle torque moment of inertia & $j_{r}$ \\
\hline $\begin{array}{c}\text { The central differential rear axle } \\
\text { angle acceleration }\end{array}$ & $\dot{\omega}_{o r}$ & $\begin{array}{l}\text { Torque distribution device } \\
\text { input angle acceleration }\end{array}$ & $\dot{\omega}_{o d}$ \\
\hline $\begin{array}{l}\text { The wind resistance of the whole machine along } \\
\text { the } x \text {-axis }\end{array}$ & $F_{w x}$ & $\begin{array}{l}\text { The wind resistance of the } \\
\text { whole machine along the } y \text {-axis }\end{array}$ & $F_{w y}$ \\
\hline Control torque factor & $k$ & Clutch control torque & $T_{c}$ \\
\hline
\end{tabular}

\subsubsection{Mathematical Model of Driving Wheels}

Drive wheel tires are the power interface between the harvesters and the ground, their structures, and mechanical characteristics are crucial to the travel and operational performance of the whole harvester [27]. To study the various cases of slippage of harvester tires on the same plane, the Gim tire model was selected in this study [28-30], and the following mechanical characteristics model of tires were established. 
In the tire rolling state:

$$
\begin{aligned}
& F_{x w}=C_{s} s_{s} l_{n}^{2}+\mu_{x} F_{z}\left(1-3 l_{n}^{2}+2 l_{n}^{3}\right) \\
& F_{y w}=C_{a} s_{a} l_{n}^{2}+\mu_{y} F_{z}\left(1-3 l_{n}^{2}+2 l_{n}^{3}\right)
\end{aligned}
$$

In the tire slipping state:

$$
\begin{aligned}
& F_{x w}=\mu_{x} F_{z} \\
& F_{y w}=\mu_{y} F_{z}
\end{aligned}
$$

the lateral camber angle of the tire was neglected in the modeling process.

At the same time, the mathematical model of each of the four driving wheels was established as follows:

$$
\begin{array}{r}
\dot{\omega}_{f l}=\dot{\omega}_{o f}+\left[\left(F_{x w f r} r_{w}+f_{f r} F_{z f r} r_{w}+M_{b f r}\right)-\left(f_{f l} F_{z f l} r_{w}+r_{w} F_{x w f l}+M_{b f l}\right)\right] /\left(2 j_{w f}\right) \\
\dot{\omega}_{f r}=\dot{\omega}_{o f}+\left[\left(f_{f l} F_{z f l} r_{w}+r_{w} F_{x w f l}+M_{b f l}\right)-\left(F_{x w f r} r_{w}+f_{f r} F_{z f r} r_{w}+M_{b f r}\right)\right] /\left(2 j_{w f}\right) \\
\dot{\omega}_{r l}=\dot{\omega}_{o r}+\left[\left(F_{x w r r} r_{w r}+f_{r r} F_{z r r} r_{w r}+M_{b r r}\right)-\left(f_{r l} F_{z r l} r_{w r}+r_{w r} F_{x w r l}+M_{b r l}\right)\right] /\left(2 j_{w f}\right) \\
\dot{\omega}_{r r}=\dot{\omega}_{o r}+\left[\left(f_{r l} F_{z r l} r_{w r}+r_{w r} F_{x w r l}+M_{b r l}\right)-\left(F_{x w r r} r_{w r}+f_{r r} F_{z r r} r_{w r}+M_{b r r}\right)\right] /\left(2 j_{w f}\right)
\end{array}
$$

the specific meanings of each parameter in Equations (8)-(11) are shown in Table 1. Meanwhile, the sub-reducer is integrated into the main reducer of the corresponding axle, and at this time, the angular velocity of the driving wheel and the corresponding half-axle are the same.

\subsubsection{Mathematical Model of Inter-Axle and Inter-Wheel Torque Distribution Device}

The active torque distribution control between the front axle drive wheels used an active torque control differential, consisting of an electronically controlled clutch, a master clutch, a common symmetrical bevel gear differential, and a triplex compound gear, which could achieve torque distribution while taking the sensitive and fast control into account [31]. The active friction plate of the clutch was fixed to one half-axle of the differential, and the two sets of driven friction plates were connected to the housing of the symmetrical bevel gear differential through a composite gear. When the clutch on the left side was combined, as shown in Figure 3a, the output torque of the right half-axle of the rear axle differential decrease, and the output torque of the left half-axle increase; the situation was reversed when the clutch on the right side was combined [32].
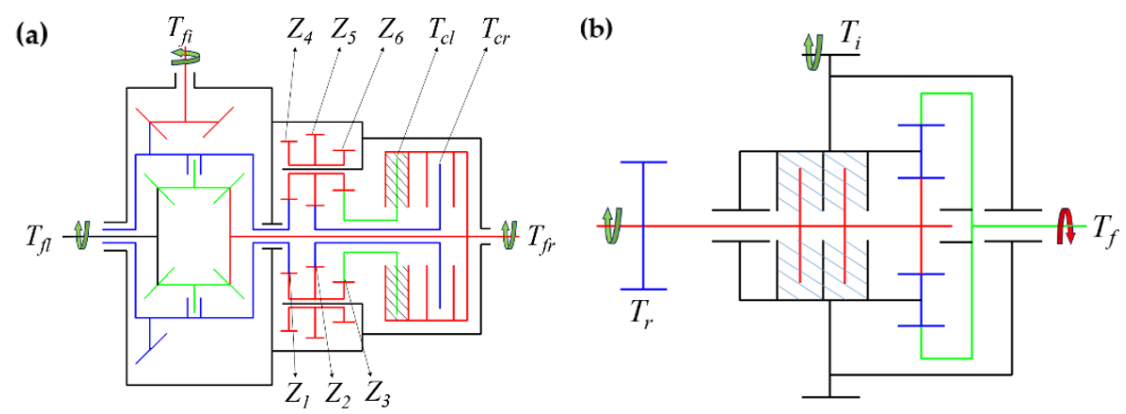

Figure 3. Torque distribution mechanism: (a) front axle torque active control differential, (b) electronically controlled central differential.

Torque distribution characteristics of the front axle torque differential when the left clutch is combined:

$$
\left\{\begin{array}{c}
T_{f l}=\frac{T_{f i}}{2}+\frac{Z_{1} Z_{6}}{2 Z_{3} Z_{4}} T_{c l} \\
T_{f r}=\frac{T_{f i}}{2}-\left(1-\frac{Z_{1} Z_{6}}{2 Z_{3} Z_{4}}\right) T_{c l}
\end{array}\right.
$$


similarly, when the right clutch is combined:

$$
\left\{\begin{array}{c}
T_{f l}=\frac{T_{f i}}{2}-\frac{Z_{1} Z_{5}}{2 Z_{4} Z_{4}} T_{c r} \\
T_{f r}=\frac{T_{f i}}{2}+\left(1-\frac{Z_{1} Z_{5}}{2 Z_{2} Z_{4}}\right) T_{c r}
\end{array}\right.
$$

where $T_{c l}$ and $T_{c r}$ are the control torques between the left and right wheels of the front axle, respectively; $T_{f i}$ is the input torque; $T_{f r}$ is the torque output to the right front wheel; $T_{f l}$ is the torque output to the left front wheel; $Z_{1}, Z_{2}, Z_{3}, Z_{4}, Z_{5}, Z_{6}$ are the number of teeth of the corresponding gears, respectively.

The inter-axle torque distribution control is implemented by an electronically controlled central planetary gear differential, the structure of which is shown in Figure $3 \mathrm{~b}$. In the figure, $T_{i}$ is the input torque; $T_{r}$ is the torque output to the rear axle; $T_{f}$ is the torque output to the front axle. The torque output from the transmission is first applied to the gears fixed to the planetary carrier, and the input torque is later distributed to the front drive axle connected to the ring gear as well as the rear-drive axle connected to the sun gear through a single row planetary gears. The torque distribution between the two axles is controlled by a control clutch between the planetary carrier and the rear output axle.

The control torque of the control clutch is

$$
T_{c}=\frac{\pi \mu_{z} \mu_{c} \varepsilon_{o} r_{z} r_{k} n p q^{2}}{4 r_{t}} I^{2}
$$

where $\varepsilon_{o}$ is the vacuum permeability; $p$ is the number of active friction plate working surfaces of the main clutch of the inter-axle differential; $n$ is the number of driven friction plate working surfaces of the main clutch of the inter-axle differential; $r_{t}$ is the armature pole radius; $q$ is the coil turns; $r_{k}$ is the effective working radius of the control clutch of the inter-axle differential; $r_{z}$ is the effective radius of the main clutch of the inter-axle differential; $\mu_{z}$ and $\mu_{c}$ are the friction coefficient of the main clutch friction plate and the control clutch friction plate, respectively. The input is the clutch control current $I$, and the output is the generated limited-slip torque [33].

The active differential can actively distribute the drive torque to the drive wheels on both sides of the axle according to the harvester driving conditions and the road condition, thus improv the driving stability of the harvester [34,35]. Friction was discarded in modeling the central differential with the drive wheels [33].

Mathematical model of the front and rear axles of the central differential:

$$
\begin{gathered}
\dot{\omega}_{o f}=\left\{\dot{\omega}_{o d}+\left[\left(F_{x w r r} r_{w r}+f_{r r} F_{z r r} r_{w r}+r_{w w r} F_{x w r l}+f_{r l} F_{z r l} r_{w}+M_{b r l}+M_{b r r}\right) z_{x} / i_{o r} z_{t}+k T_{c}\right.\right. \\
\left.\left.-\left(F_{x w f r} r_{w}+f_{f r} F_{z f r} r_{w}+r_{w} F_{x w f l}+f_{f l} F_{z f l} r_{w}+r_{w} F_{x w f l}+M_{b f l}+M_{b f r}\right) / i_{o f}\right] /\left(j_{f}+j_{r}\right)\right\} i_{o f} \\
\dot{\omega}_{o r}=\left\{\dot{\omega}_{o d}+\left[F_{x w f r} r_{w}+f_{f r} F_{z f r} r_{w}+r_{w} F_{x w o f l}+f_{f l} F_{z f l} r_{w}+r_{w w} F_{x w f l}+M_{b f l}+M_{b f r}\right) z_{t} / i_{o f} z_{x}\right. \\
\left.\left.-k T_{c}-\left(F_{x w r r} r_{w r}+f_{r r} F_{z r r} r_{w r}+r_{w r} F_{x w r l}+f_{r l} F_{z r l} r_{w}+M_{b r l}+M_{b r r}\right) / i_{o r}\right] /\left(j_{f}+j_{r}\right)\right\} i_{o r}
\end{gathered}
$$

the meaning of each parameter in Equations (15) and (16) is shown in Table 1.

\subsubsection{The Mathematical Model of Engine}

The torque controller controls the amount of engine output torque by adjusting the throttle opening. The throttle position is controlled using a proportional-integral (PI) control algorithm, the input deviation is $e$, and the output throttle opening increments is $\Delta k_{d}$.

$$
e=\frac{v_{r}}{\lambda}-\left(\omega_{1}+\omega_{2}+\omega_{3}+\omega_{4}\right) R / 4
$$

$\Delta e$ is the increment of $e$, corresponds to the increment of throttle opening as

$$
\Delta k_{d}=e k_{p}+\Delta e k_{i}
$$


in Equations (17) and (18), $k_{p}$ and $k_{i}$ are the proportional and integral factors of the harvester throttle controller, respectively; $\lambda$ is the throttle controller adjustment parameter; $v_{r}$ is the reference vehicle speed; $r_{w}$ is the driving wheel radius; $\omega_{1}, \omega_{2}, \omega_{3}$, and $\omega_{4}$ are the left front, right front, left rear, and right rear drive wheel angular velocities, respectively.

The engine speed variation is a dynamic process during the harvester start-up, and when the harvester is operating in the field, the engine is also in non-stationary operation all the time. Therefore, the engine was simplified to an inertial system, with the following dynamic mathematical model [36-39]:

$$
T_{e}=T_{e s} \frac{e^{-S T_{e 1}}}{1+S T_{e 2}}
$$

where $T_{e}$ is the output torque of the engine; $T_{e s}$ is the steady torque of the engine; $S$ is a torque characteristic coefficient of the diesel engine; $k_{d}$ is the throttle opening of the engine; $T_{e 1}$ and $T_{e 2}$ are the system time constant and the hysteresis constant, respectively.

\subsubsection{The Mathematical Model of Brakes}

The harvester has a high degree of inertia, to ensure good braking control performance, reduce the braking torque load of the brake, miniaturize the brake structure, combine the speed-torque with other mechanical relationships, this study designed a harvester brake with the mounting structure shown in Figure 4, which was not mounted directly on the drive wheels but was fastened as a component to the differential part of the harvester drive axle.

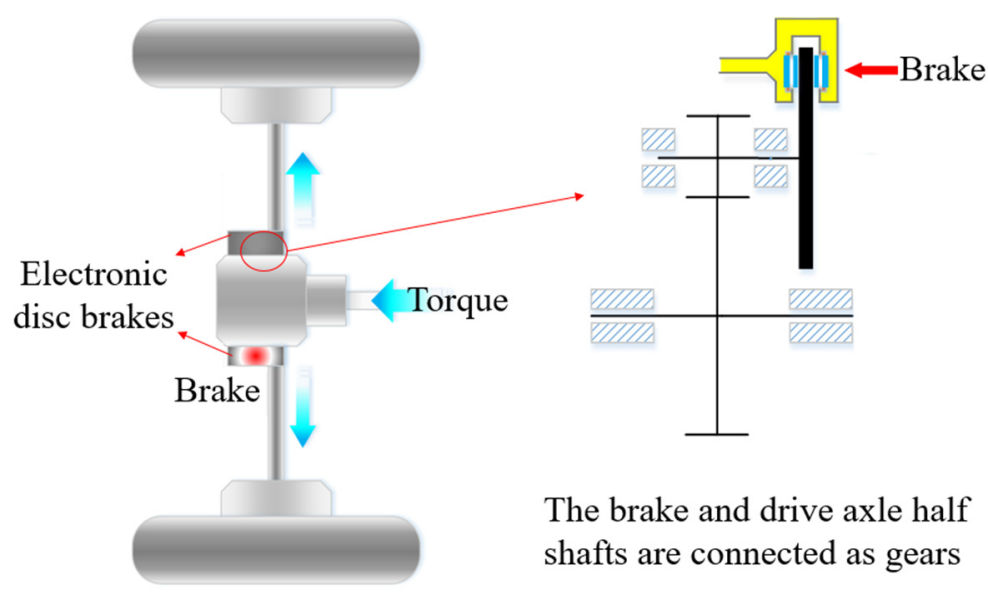

Figure 4. Brake mounting structure.

Each of the four drive wheels adopted independent floating electronically controlled disc brakes, which makes the drive torque active distribution control between the drive wheels more precise and also makes the harvester have a better safety performance. The principle of active inter-wheel torque distribution control is shown in Figure 4. If one of the two drive wheels on the same drive axle takes a certain degree of braking, the torque input to the drive axle will be transferred from the braking wheel to the other drive wheel through the differential, thus realizing the inter-wheel torque distribution control.

In this study, a logic gate algorithm was used to design the brake control system with three control states: pressurization, pressure-holding, and decompression, and the corresponding output control signals were digital in and out $(\mathrm{DIO})=1,2,3$; the input signals were the angular acceleration $\dot{\omega}$, and the relative slip rate $S_{R i}$ of the corresponding drive wheels. 
The corresponding slip rate of each tire is

$$
\left\{\begin{array}{l}
S_{R 1}=\frac{\left(\omega_{1}-\omega_{2}\right)}{\omega_{1}} \\
S_{R 2}=\frac{\left(\omega_{2}-\omega_{1}\right)}{\omega_{2}} \\
S_{R 3}=\frac{\left(\omega_{3}-\omega_{4}\right)}{\omega_{3}} \\
S_{R 4}=\frac{\left(\omega_{4}-\omega_{3}\right)}{\omega_{4}}
\end{array}\right.
$$

where $S_{R 1}, S_{R 2}, S_{R 3}$, and $S_{R 4}$ in $S_{R i} i=1,2,3,4$ are the left front, right front, left rear, and right rear drive wheel slip rates, respectively; $S_{o b}$ is the target control setting slip rate. The specific control strategy is shown in Table 2.

Table 2. Braking control strategy.

\begin{tabular}{ccc}
\hline Current Working State & Judgment Condition & $\begin{array}{c}\text { Corresponding Brake } \\
\text { Control Command }\end{array}$ \\
\hline \multirow{2}{*}{ Pressure-holding } & $S_{R i}>S_{o b}$ and $\dot{\omega}_{i}>0$ & Pressurization \\
& $S_{R i}<S_{o b}$ and $\dot{\omega}_{i}<0$ & Decompression \\
& Other & Pressure-holding \\
\hline \multirow{2}{*}{ Pressurization } & $S_{R i}<S_{o b}$ & Pressure-holding \\
& $S_{R i}>S_{o b}$ & Pressurization \\
\hline \multirow{2}{*}{ Decompression } & $\dot{\omega}_{\mathrm{i}}>0$ & Pressure-holding \\
& $\dot{\omega}_{i}<0$ & Decompression \\
\hline
\end{tabular}

On this basis, the torque model and pressure model of the brakes were established. The pressure model inputs the control signal in and outputs the pressure signal $P$. The output pressure signal $P$ is used as the input signal of the torque model to make it output the braking torque $M_{b}$.

Mathematical model of the brakes:

$$
P= \begin{cases}P_{o}+P_{\max }\left(1-e^{-t K_{t}}\right) & , \text { in }=0 \\ P_{o} & , \text { in }=1 \\ P_{o} e^{-t K_{t}} & , \text { in }=3\end{cases}
$$

the solenoid brake command in Equations (21) and (22) is entered as 0 for brake pressurization, 1 for brake pressure-holding, and 3 for brake decompression.

Where $P_{o}$ is the initial brake pressure; $t$ is the duration; $K_{t}$ is the brake braking time coefficient; $i_{b}$ is the ratio of the brake transmission mechanism; $K_{b}$ is the braking coefficient.

\section{Simulation and Result Analysis}

Combining the above design and modeling, this study proposed a three-row wheeled $4 \mathrm{WD}$ corn harvester torque active distribution control strategy, set the initial simulation conditions, simulated the established harvester models through the MATLAB/Simulink.

\subsection{Torque Control Strategy and Simulation Initial Conditions}

A combination of engine control, inter-axle torque distribution, and drive wheel braking was used to improve the traction performance and field passing ability of the harvester, and to enhance the adaptability to the complex operating environments of the harvester. According to the dynamics of the differential and the hierarchical module design, the control strategy of the harvester operation drive torque distribution was obtained, as shown in Figure 5. 


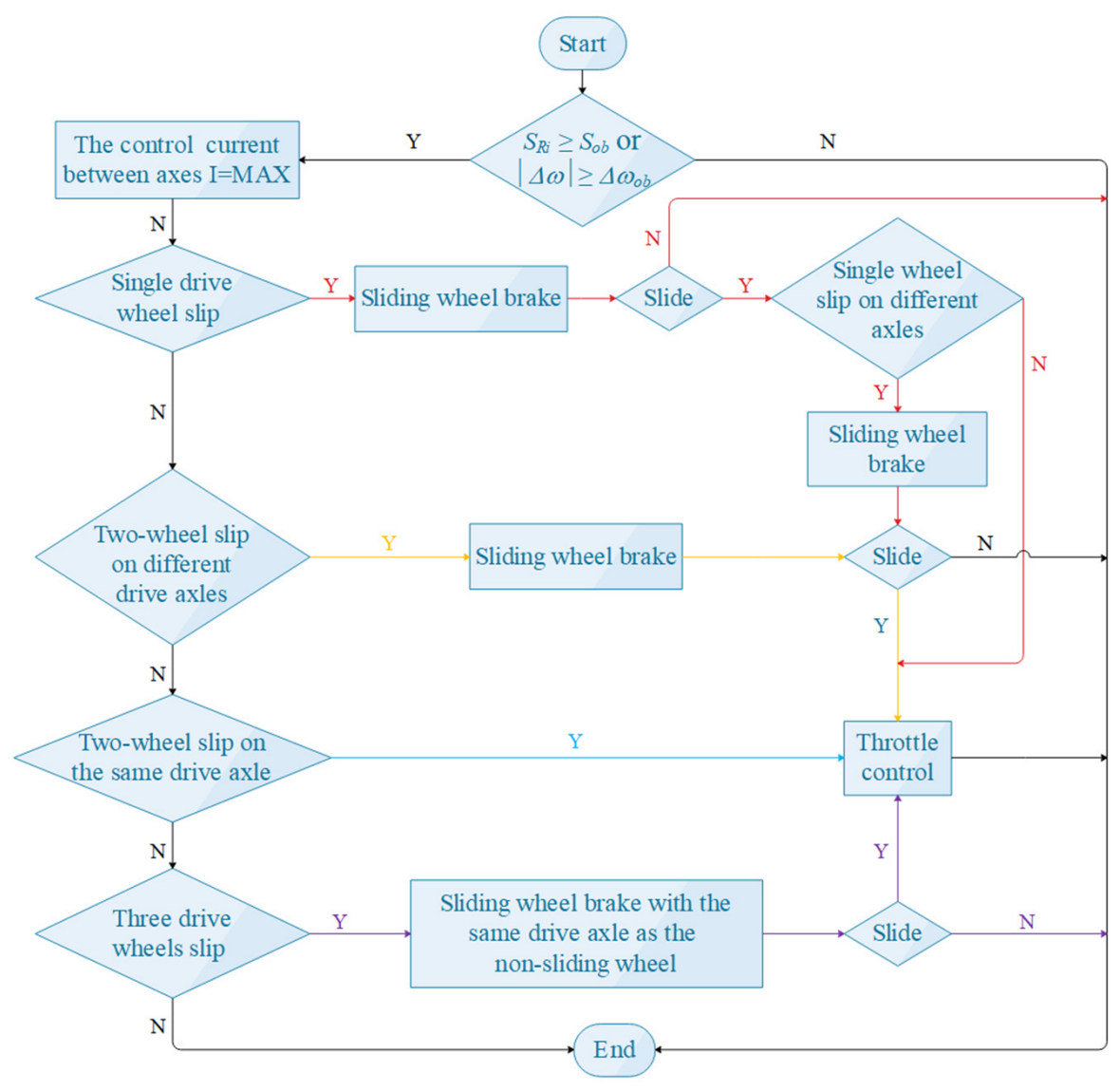

Figure 5. Harvester torque distribution control strategy.

Where, $\triangle \omega$ was the front and rear axle speed difference and $\triangle \omega_{o b}$ was the target setting value.

During the operation, there were four different working conditions as shown in Figure 6, single-wheel slip, two-wheel slip with the same axle, and different axle, singlewheel non-slip. When the slip rate of a drive wheel was greater than the target value, or the absolute value of the speed difference between the front and rear drive axles was greater than the target value, the inter-axle torque control started, the inter-axle control current was taken to the maximum value, the front and rear axle speed was adjusted to the same, and then further slip judgment and control was performed, as shown in Figure 5.
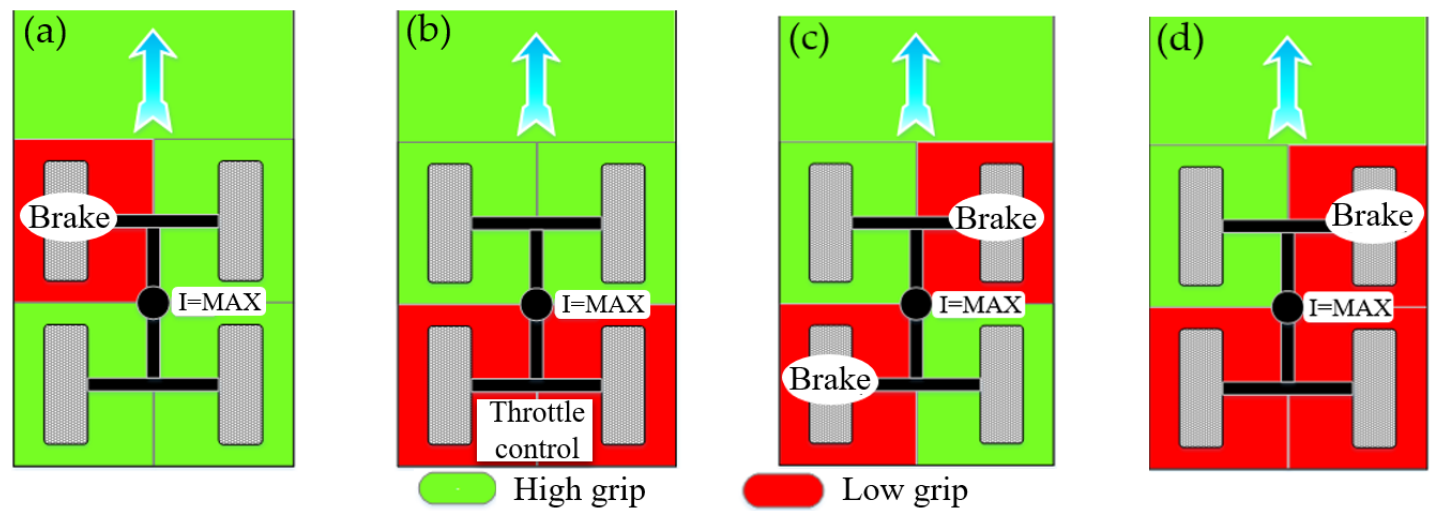

Figure 6. Four cases of preliminary control of harvester drive wheel slipping: (a) front left wheel slipping, (b) double rear wheels slipping of the same axle, (c) double wheels slipping of the different axles, (d) only the front left wheel did not slip. 
The torque control strategy of the three-row wheeled 4WD corn harvester experimental model was simulated by the MATLAB/Simulink, and the simulation results were analyzed. The main simulation parameters are shown in Table 3.

Table 3. Main parameters used in the simulation.

\begin{tabular}{|c|c|c|c|c|}
\hline Condition & Parameter & Value & Parameter & Value \\
\hline \multirow{6}{*}{ Transmission system } & Engine power $(\mathrm{kw})$ & 110 & Rated speed (r/min) & 2200 \\
\hline & Front axle gearbox ratio: $i_{o f}$ & 6.2 & Rear-axle gearbox ratio: $i_{o r}$ & 6.2 \\
\hline & Engine lag time constant: $T_{e 1}(\mathrm{~s})$ & 0.01 & Engine time constant: $T_{e 2}(\mathrm{~s})$ & 0.5 \\
\hline & $\begin{array}{l}\text { Friction coefficient of main clutch } \\
\text { friction plate: } \mu_{z}\end{array}$ & 0.25 & $\begin{array}{l}\text { Friction coefficient of control clutch } \\
\text { friction plate: } \mu_{c}\end{array}$ & 0.25 \\
\hline & $\begin{array}{l}\text { Effective working radius of the main } \\
\text { clutch: } r_{z}(\mathrm{~mm})\end{array}$ & 74 & $\begin{array}{c}\text { Control clutch effective working } \\
\text { radius: } \boldsymbol{r}_{c}(\mathrm{~mm})\end{array}$ & 74 \\
\hline & Reduction ratio of belt drive: $i_{v}$ & 2 & $\begin{array}{l}\text { Front and rear axle transmission } \\
\text { efficiency: } \mu_{o f}\end{array}$ & 0.95 \\
\hline \multirow{2}{*}{ Brakes } & Brake peak pressure: $P_{\max }\left(\mathrm{MP}_{\mathrm{a}}\right)$ & 13 & Braking system time factor: $K_{t}$ & 3.5 \\
\hline & $\begin{array}{l}\text { Front brake wheel cylinder diameter: } \\
\qquad D_{f}(\mathrm{~mm})\end{array}$ & 45 & $\begin{array}{l}\text { Rear brake wheel cylinder diameter: } \\
\qquad D_{l}(\mathrm{~mm})\end{array}$ & 35 \\
\hline Wheels & Drive wheel rolling radius (m) & 0.6 & Tire section width (mm) & 315 \\
\hline \multirow{3}{*}{ Whole machine } & Harvester quality $(\mathrm{kg})$ & 4600 & Front and rear wheelbase (mm) & 3000 \\
\hline & $\begin{array}{l}\text { Moment of inertia of the whole } \\
\text { machine around } z \text {-axis: } J_{z}\left(\mathrm{~kg} \cdot \mathrm{m}^{2}\right)\end{array}$ & 7360 & $\begin{array}{l}\text { Distance of the mass center from the } \\
\text { front axis: } a(\mathrm{~mm})\end{array}$ & 1220 \\
\hline & Front axle wheelbase $(\mathrm{mm})$ & 1600 & Rear-axle wheelbase (mm) & 1600 \\
\hline Road state & Field adhesion coefficient: $\mu_{t}$ & 0.6 & $\begin{array}{l}\text { Coefficient of rolling resistance in } \\
\text { field: } f_{R}\end{array}$ & 0.1 \\
\hline
\end{tabular}

The initial position of the simulation is shown in Figure 7, with good road conditions, an initial speed of $3 \mathrm{~m} / \mathrm{s}$, a slope angle of $10^{\circ}$, an accelerator pedal of $100 \%$, and the wheel steering angle of $0^{\circ}$. Figure 6 shows the schematic diagram of the initial control based on the inter-axle torque control.

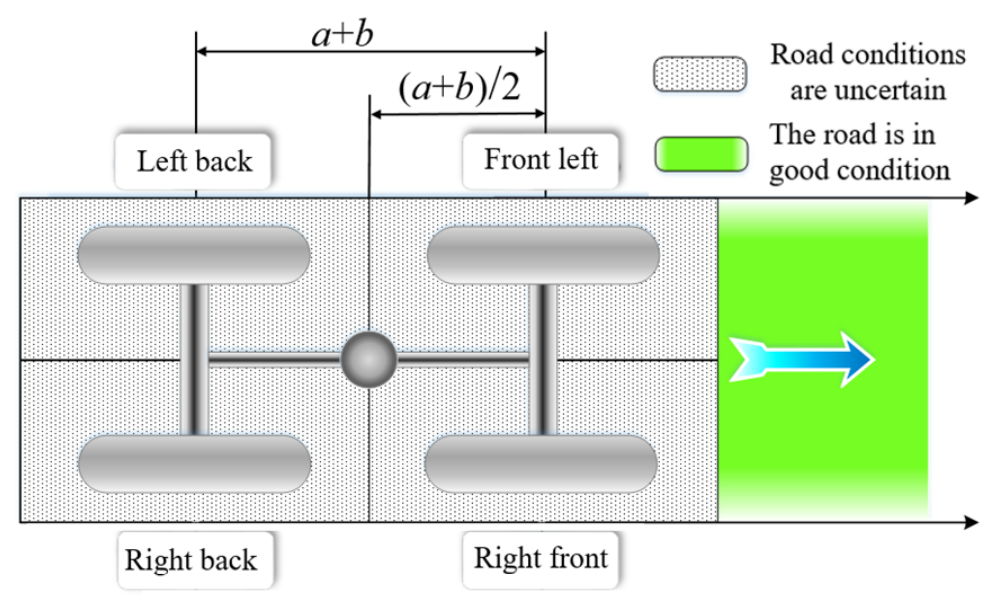

Figure 7. Initial state of harvester simulation.

\subsection{Front Left Wheel Slip Simulation}

The initial state of the simulation was the left front wheel slipping, after the inter-axle torque control. The adjustment control process was to brake the slipping wheel to a certain extent based on the inter-axle differential clutch combination, so that part of the driving torque was transferred to the well-attached driving wheels, and if it slipped again, further torque control was carried out, and if necessary, engine output torque control was carried out in conjunction with engine throttle control. Finally, the traction force of the whole 
machine was improved. The simulation results are shown in Figure 8a,b. The dashed lines were the variation law of the harvester speed and the speed of the slipping wheel with time when no control was applied, and the solid lines were the corresponding speed variation law after the control was applied.
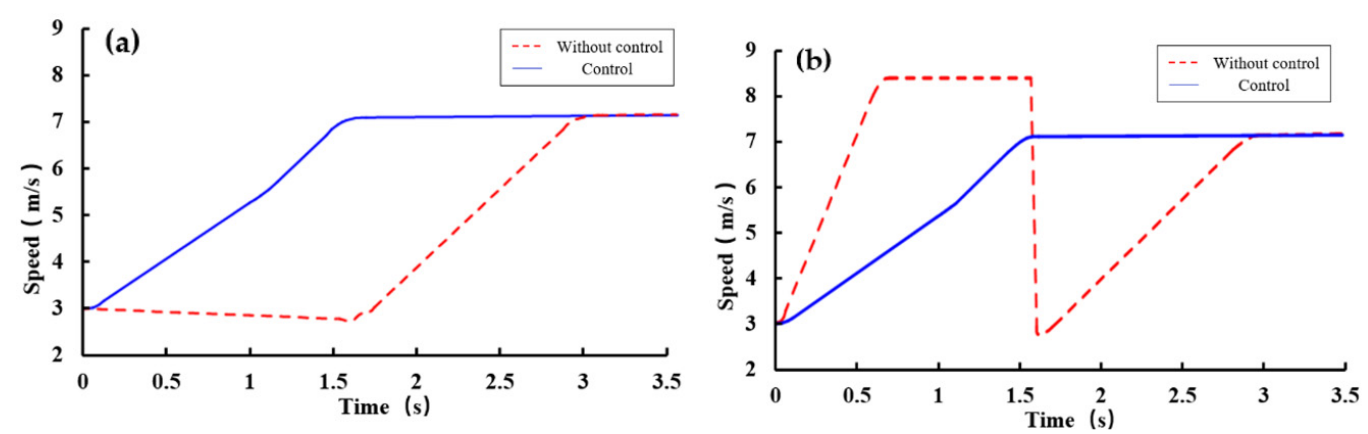

Figure 8. Simulation results of the harvester with only the front left wheel slipping: (a) Harvester speed; (b) slipping wheel speed.

The simulation results showed, when no control was applied to the harvester, within $1.7 \mathrm{~s}$, the speed of the slipping wheel first rose sharply to the maximum value due to slippage and then fell sharply to below $3 \mathrm{~km} / \mathrm{h}$ due to the increase in attachment, during which the speed of the harvester showed a decreasing trend due to the slip of the wheel. After $1.7 \mathrm{~s}$, the speed of the harvester increased with the speed of the slipping wheel and finally reached the uniform speed at the same time. The harvester speed and the slip wheel speed fluctuated greatly during the whole process, and the speed of the slip wheel was overshoot, the maximum overshoot was $17.86 \%$; after the torque control was applied, as shown in the solid line in Figure 8, the speed of the harvester and the speed of the slipping wheel rose steadily during the whole adjustment process, and the adjustment time to reach the uniform speed was $43.3 \%$ shorter than that without control.

In summary, active torque control distribution could quickly eliminate single drive wheel slippage, and improve the passing ability and driving stability of the harvester during operation.

\subsection{Simulation of Double Rear Wheels Slip with the Same Axle}

The initial state of the simulation was the slipping of the rear axle double drive wheels, after the inter-axle torque control. Since both wheels of the rear axle were in the slipping state, the inter-wheel torque control failed to operate, and the adjustment process was controlled by the engine output to eliminate the slipping. The simulation results are shown in Figure 9a,b.
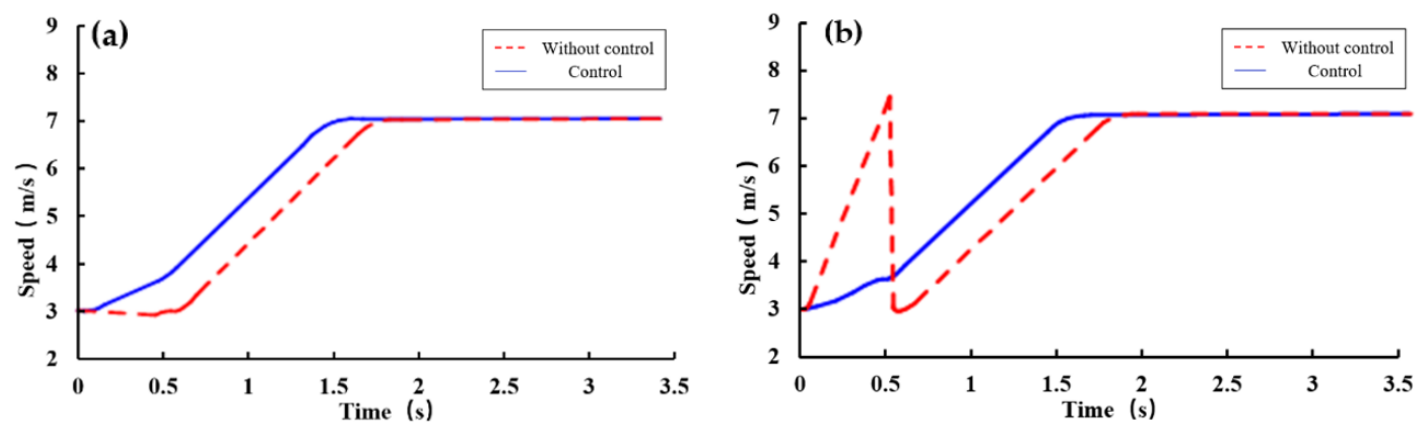

Figure 9. Simulation results of the harvester with the double rear wheels of the same axle are slipping: (a) Harvester speed, (b) average speed of slipping wheels. 
From the simulation results, when no control was applied to the harvester, within $0.6 \mathrm{~s}$, the average speed of the slipping wheels first rose sharply to the maximum value due to slippage and then fell sharply to below $3 \mathrm{~km} / \mathrm{h}$ due to the increase in attachment, during which the speed of the harvester showed a decreasing trend due to wheels slippage. After $0.6 \mathrm{~s}$, the speed of the harvester rose with the speed of the slip wheels and finally reached the uniform speed at the same time. The harvester speed and the average speed of the slip wheels fluctuated greatly during the whole process, and the average speed of the slip wheels was overshoot, the maximum overshoot was 3.57\%; after the control was applied, as shown in the solid line in Figure 9, the harvester speed and the average speed of the slip wheels were in a steady rise during the whole adjustment process, and the adjustment time to reach the uniform speed was $11.1 \%$ shorter than that when the control was not applied.

In summary, active torque control distribution could effectively eliminate double rear wheels slip with the same axle, and improve the passing ability as well as driving stability of the harvester during operation.

\subsection{Simulation of Two-Wheel Slip with Different Axles}

The initial state of the simulation was the front right and rear left drive wheels slipping after inter-axle torque control, and the adjustment process was to perform slipping wheels braking based on the initial inter-axle torque control so that some drive torque on the slipping wheels was transferred to the well-attached drive wheels, and if they slipped again, further engine output torque control was applied. Finally adjusted to no drive wheels slipping. The simulation results are shown in Figure 10a,b.
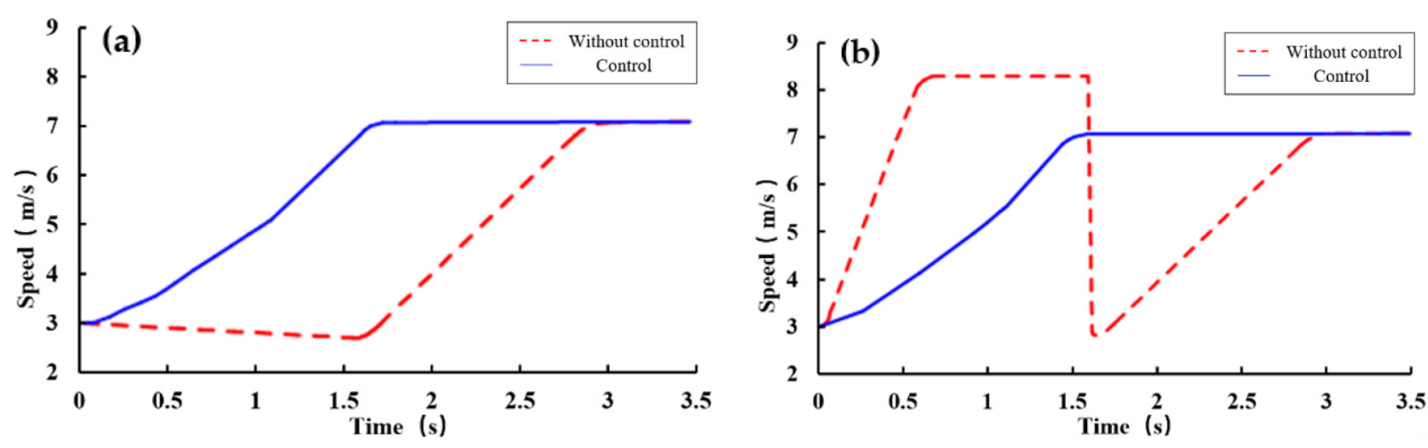

Figure 10. Simulation results of the harvester with two wheels slipping on the different axles: (a) harvester speed, (b) average speed of slipping wheels.

From the simulation results, when no control was applied to the harvester, within $1.7 \mathrm{~s}$, the average speed of the slip wheels first rose sharply to the maximum value due to slippage and then fell sharply to below $3 \mathrm{~km} / \mathrm{h}$ due to the increase in attachment, during which the speed of the harvester showed a decreasing trend due to wheels slippage. After $1.7 \mathrm{~s}$, the harvester speed increased with the average speed of the slip wheels and finally reached the uniform speed at the same time. The harvester speed and the speed of the slip wheel fluctuated greatly during the whole process, and the speed of the slip wheel was overshoot, the maximum overshoot was $17.14 \%$; after the control was applied, as shown in the solid line in Figure 10, the speed of the harvester and the average speed of the slip wheels increased steadily during the whole adjustment process, and the adjustment time to reach the uniform speed was $41.4 \%$ shorter than that when the control was not applied.

In summary, active torque control distribution could effectively eliminate two-wheel slip with different axles, and improve the passing ability as well as the driving stability of the harvester during operation. 


\subsection{Simulation When Only the Front Left Wheel Does Not Slip}

The initial state of the simulation was a state where only the front left wheel did not slip after inter-axle torque control. The adjustment control process was to apply a certain degree of braking to the corresponding slipping wheels based on the inter-axle differential clutch combination so that the part of the driving torque was transferred to the left front drive wheel; if it slipped again, further torque control was carried out, and if necessary, engine output torque control was implemented to finally improve the traction. The traction force of the whole machine was finally improved. The simulation results are shown in Figure $11 \mathrm{a}, \mathrm{b}$.
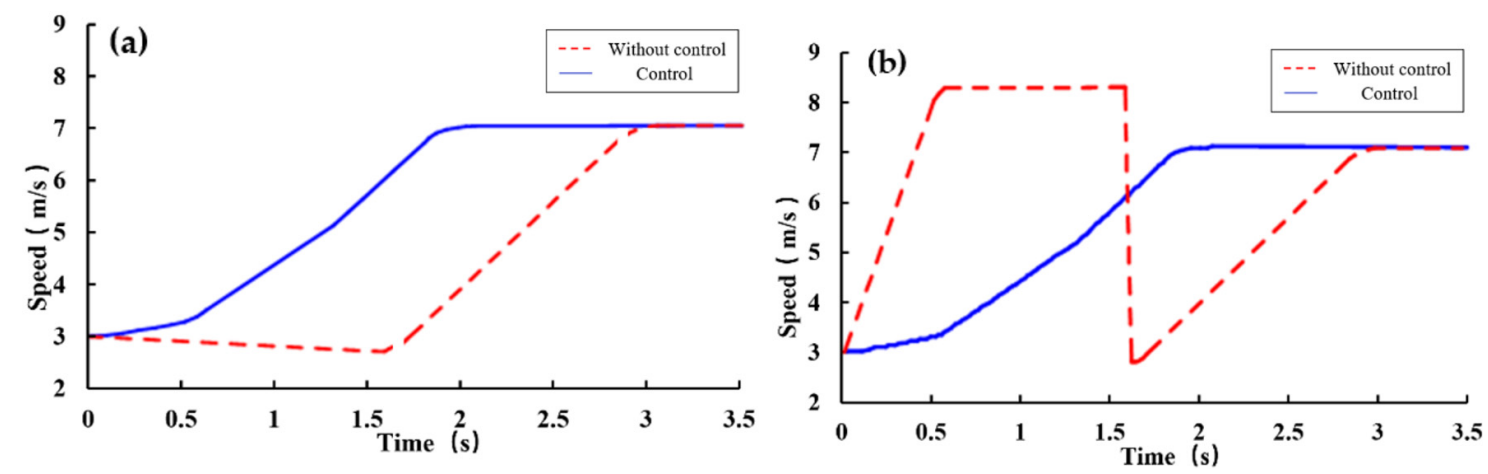

Figure 11. Simulation results where only the front left wheel of the harvester was not slipping: (a) Harvester speed, (b) Average speed of slipping wheels.

The simulation results showed, when no control was applied to the harvester, within $1.6 \mathrm{~s}$, the average speed of the slip wheels first rose sharply to the maximum value due to slippage and then fell sharply to below $3 \mathrm{~km} / \mathrm{h}$ due to the increase in attachment, and the speed of the harvester showed a decreasing trend due to wheels slippage during the process. After $1.6 \mathrm{~s}$, the speed increased with the average speed of the slip wheels and finally reached the uniform speed at the same time. The harvester speed and the speed of the slip wheel fluctuated greatly during the whole process, and the speed of the slip wheel was overshoot, the maximum overshoot was $17.14 \%$; after the control was applied, as shown in the solid line in Figure 11, the speed of the harvester and the average speed of the slip wheels increased steadily during the whole adjustment process, and the adjustment time to reach the uniform speed was $36.6 \%$ shorter than that when the control was not applied. From the speed change curve, it could be qualitatively analyzed that in the process of adjusting the harvester drive wheel slippage, the tractive force of both the whole harvester and the well-attached drive wheels increased after the torque control was applied compared with that without the torque control, which was able to make the adjustment time shorter.

In summary, active torque control distribution could effectively eliminate threewheel slip, and improve the passing ability as well as driving stability of the harvester during operation.

\subsection{Qualitative Analysis of the Traction Force}

The changes of traction force during the whole adjustment process could be analyzed qualitatively by the changes in the average speed of harvester and slipped wheels. During the adjustment process, there are two variables, driving torque and road adhesion, which affect the changes of traction force of harvester and driving wheels. A sharp decline in ground adhesion causes the harvester driving wheels to slip, at this time, if the harvester does not apply torque control, the torque is not redistributed, and the traction force of harvester slipping driving wheels decreases while the traction force of non-slip driving wheels remains unchanged, resulting in the traction force of the harvester as a whole not 
being supplemented after the decline. If the torque control is applied when the driving wheel is slipping, the torque of each driving wheel of the harvester is redistributed, and the torque on the slipping wheels is redistributed to other driving wheels with good grip after braking, and as the grip of other driving wheels is not reduced, the driving torque increases, increasing tractive force, thus increasing the tractive force of the whole harvester and reducing the time of harvester slipping adjustment. Finally, in the next stage, we will quantitatively analyze the traction force of the whole harvester and the drive wheels.

\section{Conclusions}

The results showed that with both inter-axle and inter-wheel torque control in operation, the adjustment time for harvester drive wheel slippage was reduced by more than 35\% compared to without control. When the inter-wheel torque distribution control failed to work in the case of double drive wheels slipping on the same axle, the adjustment time was still shortened by $11.1 \%$ than without control. Before the applied torque control, the speed fluctuation was obvious, the average speed of the slipping wheels was overshoot, and the maximum overshoot was $17.86 \%$ in the case of the front left wheel slip. After applied the torque control, the overshoot phenomenon was eliminated and the speed fluctuation was significantly reduced.

The drive torque distribution control could improve the traction performance and field passing ability of the three-row 4WD corn harvester, enhance its adaptability to the complex field environment, effectively reduce the speed fluctuation during operation, and greatly improve the harvesting quality of the harvester. In addition, real-time torque control could distribute the torque from the slipping wheels to other well-attached driving wheels, which effectively avoids power waste and plays an energy-saving role. This study also provides a new methodology for the design and improvement of drive systems on harvesters and other walking agricultural machinery.

Author Contributions: Conceptualization, D.Z. and B.W.; validation, P.H., Y.X. and X.L.; writingoriginal draft, P.H.; writing—review and editing, D.Z. and B.W.; supervision, J.Z., H.Y. and Q.Z. All authors have read and agreed to the published version of the manuscript.

Funding: This research was supported by the Key Projects of Science and Technology Development Plan of Jilin Province, China (Grant no. 20170204015NY); Provincial School Joint Construction Project of Jilin Province, China (Grant no. SXGJXX2017-6); the National Key Research and Development Program of China (Grant no. 2016YFD070190103).

Conflicts of Interest: The authors declare no conflict of interest.

\section{References}

1. Xu, J.; Meng, J.H.; Quackenbush, L.J. Use of remote sensing to predict the optimal harvest date of corn. Field Crop Res. 2019, 236, 1-13. [CrossRef]

2. Ferraretto, L.F.; Shaver, R.D.; Luck, B.D. Silage review: Recent advances and future technologies for whole-plant and fractionated corn silage harvesting. J. Dairy Sci. 2018, 101, 3937-3951. [CrossRef] [PubMed]

3. Shao, Y.E.; Dai, J.T. Integrated Feature Selection of ARIMA with computational intelligence approaches for food crop price prediction. Complexity 2018, 2018, 1-17. [CrossRef]

4. Wang, Y.J.; Yang, F.Z.; Pan, G.T.; Liu, H.Y.; Liu, Z.J.; Zhang, J.Q. Design and testing of a small remote-control hillside tractor. Trans. $A S A B E$ 2014, 57, 363-370.

5. Sun, C.R.; Nakashima, H.; Shimizu, H.; Miyasaka, J.; Ohdoi, K. Physics engine application to overturning dynamics analysis on banks and uniform slopes for an agricultural tractor with a rollover protective structure. Biosyst. Eng. 2019, 185, 150-190. [CrossRef]

6. Qi, W.C.; Zhang, J.H. Dual closed-loop fuzzy PID control method for tractor body leveling in hilly areas. J. Agric. Mach. 2019, 50, 17-23, 34.

7. Geng, A.J.; Zhang, M.; Zhang, J.; Zhang, Z.L.; Gao, A.; Zheng, J.L. Design and test of automatic height control system for corn harvester cutting platform. J. Agric. Mach. 2020, 51, 118-125.

8. Naunhei-mer, H.; Ryborz, J.; Bertsche, B.; Song, J.J.; Gong, S.Y. Automotive Transmission Principle Selection Design and Application; Machinery Industry Press: Beijing, China, 2013. 
9. Janulevicius, A.; Juostas, A.; Pupinis, G. Estimation of tractor wheel slippage with different tire pressures for 4WD and 2WD wheel drive systems. In Proceedings of the Engineering for Rural Development-International Scientific Conference, Jelgava, Latvia, 22-24 May 2019; pp. 88-93.

10. Piyabongkarn, D.; Lew, J.Y.; Rajamani, R.; Grogg, J.A. Active driveline torque-management systems. IEEE Control Syst. 2010, 30, 86-102.

11. Chen, L.Q.; Tan, Y.D.; Wu, R.; Miao, W.; Hu, F. Torque distribution control strategy of electronically controlled four-wheel drive axle based on genetic algorithm. Soc. Agric. Mach. 2017, 48, 361-367.

12. Ge, A.L.; Guo, L.S.; Zhang, T. Study of electronically controlled optimal torque distribution system for 4WD. J. Agric. Mach. 2002, 6, 16-19.

13. Wong, A.; Kasinathan, D.; Khajepour, A.; Chen, S. Integrated torque vectoring and power management framework for electric vehicles. Control Eng. Pract. 2016, 48, 22-36. [CrossRef]

14. De, N.L.; Sorniottia, G.P.; Gruber, P. Wheel torque distribution criteria for electric vehicles with torque-vectoring differentials. IEEE Trans. Veh. Technol. 2014, 63, 1593-1602.

15. Hyeongcheol, L. Four-wheel drive control system using a clutch lesscentre limited slip differential. Proc. Inst. Mech. Eng. Part D J. Automob. Eng. 2006, 220, 665-681.

16. Wang, J.H.; Wang, Y.C.; Fu, T.J. Study on the effect of torque type limited slip differential on the handling stability of rear wheel drive vehicles. Automot. Eng. 2006, 28, 460-464.

17. Shi, J.P.; Sun, Q.H. Theoretical Study on Determination of Torque Distribution Ratio of Splitter. Automot. Eng. 2007, 29, 889-892.

18. Wheals, J.C.; Deane, M.; Drury, S.; Griffith, G.; Harman, P.; Parkinson, R.; Shepherd, S.; Turner, A. Design and Simulation of a Torque Vectoring ${ }^{\mathrm{TM}}$ Rear Axle. In Proceedings of the SAE 2006 World Congress \& Exhibition, Detroit, MI, USA, 3-6 April 2006.

19. Hancock, M.J.; Williams, R.A.; Gordon, T.J.; Best, M.C. A comparison of braking and differential control of road vehicle yaw-sideslip dynamics. Proc. Inst. Mech. Eng. Part D J. Automob. Eng. 2005, 219, 309-327. [CrossRef]

20. Domenico, B.; Alessandro, B.; Maria, D.; Di, B.; Di, G.; Burgio, G. Adaptive Integrated Vehicle Control using Active Front Steering and Rear Torque Vectoring. Int. J. Auto Veh. Syst. 2010, 8, 85-105.

21. Jalali, M.; Hashemi, E.; Khajepour, A.; Chen, S.K.; Litkouhi, B. Integrated model predictive control and velocity estimation of electric vehicles. Mechatronics 2017, 46, 84-100. [CrossRef]

22. Hayat, S.; Ahmed, S.; Tanveerul, H.; Jan, S.; Qureshi, M.; Najam, Z.; Wadud, Z. Hybrid control of PV-FC electric vehicle using Lyapunov based theory. Int. J. Adv. Comput. Sci. Appl. 2019, 10, 539-549. [CrossRef]

23. Suzuki, R.; Ikeda, Y. Driving/braking force distribution of four wheel vehicle by quadratic programming with constraints. J. Syst. Des. Dyn. 2010, 6, 4882-4889.

24. Roman, D.; Roman, D.; Yuriy, G. Power Distribution Control in the Transmission of the Perspective Wheeled Tractor with Automated Gearbox. In Proceedings of the International Scientific Conference Energy Management of Municipal Transportation Facilities and Transport EMMFT 2017, Khabarovsk, Russia, 10-13 April 2017; pp. 192-200.

25. Wong, J.Y. Theory of Ground Vehicles; John Wiley \& Sons: Haboken, NJ, USA, 2001.

26. Wei, Y.T.; Feng, X.J.; Feng, Q.Z. Advances in Tire Dynamic Modeling Research. J. Auto Saf. Energy Conserv. $2014,4,311-323$.

27. Qiang, Q.Y.; Ying, T. A Model Predictive Controller with Longitudinal Speed Compensation for Autonomous Vehicle Path Tracking. Appl. Sci. 2019, 22, 4739.

28. Gim, G.; Nikravesh, P.E. An analytical model of pneumatic tyres for vehicle dynamic simulations. Part 2: Comprehensive Slips. Int. J. Veh. Des. 1991, 12, 19-39.

29. Gim, G.; Nikravesh, P.E. An analytical model of pneumatic tyres for vehicle dynamic simulations. Part 3: Validation against experimental data. Int. J. Veh. Des. 1991, 12, 217-228.

30. Gim, G.; Nikravesh, P.E. An analytical model of pneumatic tyres for vehicle dynamic simulations. Part 1: Pure slips. Int. J. Veh. Des. 1990, 11, 589-618.

31. Ohba, M.; Suzuka, H.; Yamamoto, T.; Takuno, H. Development of a New Electronically Controlled 4WD System: Toyota Active Torque Control 4WD. SAE Int. 1999, 108, 1326-1332.

32. Hu, J.J.; Liu, H.; He, Z.B. Effect of drive force distribution control on vehicle steering driving stability. China J. Highw. Transp. 2013, 26, 183-190.

33. Lv, X.L. Study on the Control of Drive Torque Distribution of 4WD Corn Harvester. Master's Thesis, Jilin University, Jilin, China, June 2016.

34. Hancock, M.J.; Williams, R.A.; Fina, E.; Best, M.C. Yaw motion control via active differentials. Trans. Inst. Meas. Control 2007, 29, 137-157. [CrossRef]

35. Park, J.; Jang, I.G.; Hwang, S. Torque Distribution Algorithm for an Independently Driven Electric Vehicle Using a Fuzzy Control Method: Driving Stability and Efficiency. Energies 2018, 11, 3479. [CrossRef]

36. Feng, N.; Zheng, M. Dynamic Performance Simulation of Power Shift Clutch During Shift. J. Beijing Inst. Technol. 2000, 19, 445-450.

37. Uwe, K.; Lars, N. Automotive Control Systems: Engine, Driveline and Vehicle Control; Higher Education Press: Beijing, China, 2004.

38. Yang, S.; Lee, C. Exhaust Gas Characteristics According to the Injection Conditions in Diesel and DME Engines. Appl. Sci. 2019, 9, 647. [CrossRef]

39. Li, S.; Li, X.Y.; Li, Z.Q. Automotive Engine Dynamic Process and its Control; People's Traffic Publishing House: Beijing, China, 2000. 